\title{
Penyuluhan dan Pelatihan Tentang Pembuatan Sistem Irigasi Lep Pipa Pada Jaringan Irigasi Air Tanah Dalam Di Dusun Arungan Bali Desa Akar Akar Kabupaten Lombok Utara
}

\author{
I Dewa Gede Jaya Negara*, Anid Supriyadi, Atas Pracoyo \\ Jurusan Teknik Sipil, Fakulas Teknik, Universitas Mataram, Mataram, Indonesia. \\ Jalan Majapahit, No 62, Kota Mataram, Provinsi NTB, 83115
}

\author{
Article history \\ Received: 14-06-2020 \\ Revised: 14-07-2020 \\ Accepted:15-07-2020 \\ *Corresponding Author: \\ I Dewa Gede Jaya Negara \\ Jurusan Teknik Sipil, Fakulas \\ Teknik, Universitas Mataram, \\ Mataram, Indonesia \\ Email: \\ jayanegara69@gmail.com
}

\begin{abstract}
At present in the dry land of Akar Akar Village, the government has built no less than 22 ground water pumping wells since 1990. on the land. Arungan Bali as one of the locations of dry land with potential land that is pivot and sandy, 6 hours to 8 hours per hectare of land. The irrigation period is long and very wasteful of ground water, requiring very expensive costs. To overcome this, it is necessary to develop a network of existing JIAT with a lep pipe system to improve irrigation in land plots. Based on the results of field tests the pipe lep irrigation system can provide land faster than the existing JIAT system. For that, the pipe-pipe irrigation network needs to be restored to the farming community and given training, so that the plantation method is easy for the community to imitate. This dedication is carried out by extension methods and training in making pipeline irrigation in dry land. In counseling discussions and questions and answers, while in the training carried out the manufacture of irrigation networks in plots of land. The results of this dedication show that, the Arungan Bali farmer community has gained knowledge about plantations and can create a pipe irrigation network in a plot of land. The community can make a land network because an example already exists in the land around the residents' land. $30 \%$ of the ways that already exist.
\end{abstract}

Keywords: pipe width; irrigation time efficiency; training

Abtrak: Saat ini di lahan kering Desa Akar Akar telah dibangun pemerintah tidak kurang dari 22 buah sumur pompa air tanah dalam yang sejak tahun 1990. Pembangunan sumur tersebut ditujukan unutuk mendorong kegiatan pertanian di lahan kering, yang selama ini masih banyak menemui kendala ditingkat lapang dalam memberi irigasi di lahan. Arungan Bali sebagai salah satu lokasi lahan kering dengan potensi lahan yang poros dan pasiran, irigasi ke lahan dibutuhkan waktu 6 jam sampai 8 jam per hektar lahan. Lama waktu irigasi tersebut termasuk lama dan sangat boros air tanah, mengakibatkan biaya air sangat mahal. Untuk mengatasi hal tersebut perlu dilakukan pengembangan jaringan dari JIAT yang ada dengan sistem pipa lep untuk mempercepat irigasi di peta-petak lahan. Berdasarkan hasil uji lapangan sistem irigasi lep pipa dapat memberi irigasi lebih cepat dilahan dari pada sistem JIATyang sudah ada. Untuk itu jaringan irigasi leb pipa perlu suluhkan ke masyarakat tani dan diberikan pelatihan, agar metode irigasi tersebut mudah ditiru masyarakat. Pengabdian ini dilakukan dengan metode penyuluhan dan pelatihan pembuatan jaringan irigasi leb pipa di lahan kering. Dalam penyuluhan dilakukan 
diskusi dan tanyajawab, sedangkan dalam pelatihan dilakukan pembuatan jaringan irigasi leb di petak lahan. Hasil pengabdian ini menunjukkan bahwa, masyarakat tani Arungan Bali telah mendapatkan pengetahuan pentingnya irigasi dan dapat membuat jaringan irigasi leb pipa di petak lahan. Masyarakat dapat membuat jaringan irigasi leb pipa secara sadaya karena contohnya sudah ada di lahan sekitar lahan warga. Sistem irigasi leb pipa dapat menghemat biaya irigasi sekitar $30 \%$ dari cara yang sudah ada.

Kata Kunci: leb pipa; efisiensi waktu irigasi; pelatihan

\section{PENDAHULUAN}

Pengembangan pertanian dilahan kering di propvinsi NTB sampai saat ini terus dilakukan, dan Lombok Utara salah satu diantaranya terus berupaya melakukan pengembangan pertanian di lahan kering. Sejak 1990 telah banyak dibangun sumur pompa air tanah dalam oleh pemerintah lengkap dengan jaringan irigasinya untuk mendukung kegiatan pertanian di lahan kering. Akan tetapi dalam perjalanannya, pembangunan pertanian dilahan kering masih banyak menemui kendala ditingkat lapang yang menghambat pembangunan pertanian dilahan kering. Kondisi tanah yang poros dan tanah pasiran seperti di Arungan Bali memerlukan irigasi selama waktu 6 jam sampai 8 jam per hektar lahan dan ternyata sangat boros air sehingga mengakibatkan biaya air sangat mahal dan kurang menguntungkan petani. Misalnya satu jam irigasi diperlukan 5 liter solar dengan harga solar dilapangan saat ini sekitar Rp.8000 per liter, untuk 1 ha lahan diperlukan 8 jam irigasi maka, dalam sekali irigasi diperlukan biaya sebesar Rp 8000,- x 5 liter x 8 jam = Rp 320.000, dan untuk 12 kali (sampai panen), maka biaya irigasi yang diperlukan sebesar $12 \times \mathrm{Rp} 360.000$,- $=\mathrm{Rp} 3.840 .000$,- dan belum termasuk biaya pengolahan lahan dan pemeliharaan tanaman. Menghadapi kondisi tersebut, maka petani menjadi kurang tertarik, karena penggunaan air irigasinya kurang hemat. Untuk menjawab hal di atas salah satunya dapat mencoba menggunakan hasil penelitian Jaya Negara, dkk., 2016,dimana dengan sistem irigasi leb pipa pada lahan kering tanah bergradasi halus dan dalam waktu 20 menit mampu memberi kebasahan lahan sampai hingga kedalaman $30 \mathrm{~cm}$ dan lebih merata, sedangkan pada sistem JIAT untuk memperoleh kedalaman yang sama diperlukan waktu 38 menit. Dengan demikian sistem leb pipa dapat menghemat waktu irigasi sekitar 18 menit dari pada sistem JIAT.

Memperhatikan banyaknya kendala irigasi yang ditemui dalam penerapan JIAT di lapangan, maka perlu dilakukan peningkatan efisiensi dan efektifitas air dengan teknik irigasi yang sederhana yang dapat ditiru masyarakat. Contoh-contoh ditingkat lapangan perlu diberikan sebagai sarana latihan masyarakat agar dapat membuat irigasi yang lebih hemat. Saat ini di desa Akar Akar terdapat tidak kurang dari 22 buah sumur pompa air tanah dalam, akan tetapi pemanfaatannya masih sangat rendah, sehingga perlu memperoleh penyuluhan dan pelatihan teknik-teknik irigasi efisien dan lebih sederhana seperti irigasi leb pipa, yang dapat ditiru langsung oleh masyarakat tani. 


\section{METODE}

\section{Tahap Persiapan}

Untuk dapat menjadi alternatif untuk menjawab kendala di atas, maka pengabdiaan ini akan dilakukan dengan tahapan-tahapan sebagai berikut :

1. Survey lapangan,

2. Koordinasi dengan warga dan pemuka masyarakat.

3. Koordinasi jadwal pengabdian dengan warga

4. Penyiapan bahan penyuluhan dan pelatihan pembuatan jaringan irigasi leb pipa.

\section{Tahap Pelaksanaan}

Penyuluhan dan pelatihan ini dilakukan dengan tahapan sebagai berikut:

1. Penyuluhan tentang irigasi leb pipa

2. Pembelian pipa 2,5 " dan asesorisnya

3. Pembuatan skema jaringan untuk lahan.

4. Penggalian jalur jaringan pipapvc.

5. Pemasangan jaringan pipa dan perlengkapannya.

6. Pembuatan lubang outlet irigasi dilakukan pada titik-titik tertentu pada jaringan pipa secara proporsional.

7. Uji aplikasi di lahan warga.

\section{Tahap Evaluasi}

1. Evaluasi kegiatan dilakukan pada tiap sesi, seperti pada saat baik saat pembuatan jaringan irigasi leb pipa, dan saat penjelasan pada sesi penyuluhan.

1. Pembuatan laporan pengabdian dan publikasi.

2. Perancangan jaringan jalur pipa

3. Pembersihan lahan dan membuat bentuk lahan untuk irigasi;

\section{HASIL DAN PEMBAHASAN}

\section{Tahapan Persiapan}

Tahapan persiapan pelatihan diawali dengan pemberian materi penyuluhan tentang sistem irigasi hemat air dilahan kering, warga pemilik lahan diajak diskusi dan disuluh oleh tim penyuluhan di perumahan warga disektar lahan kering.

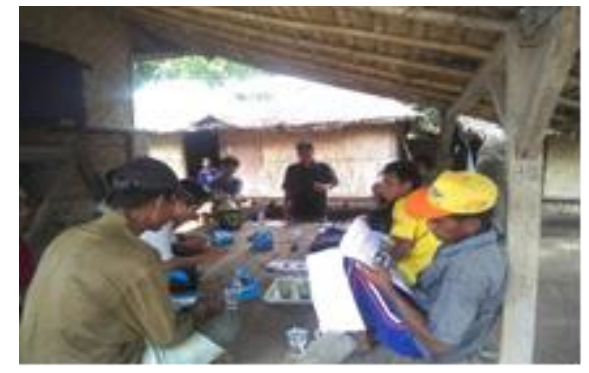

Gambar 1. Penyuluhan pentingnya irigasi
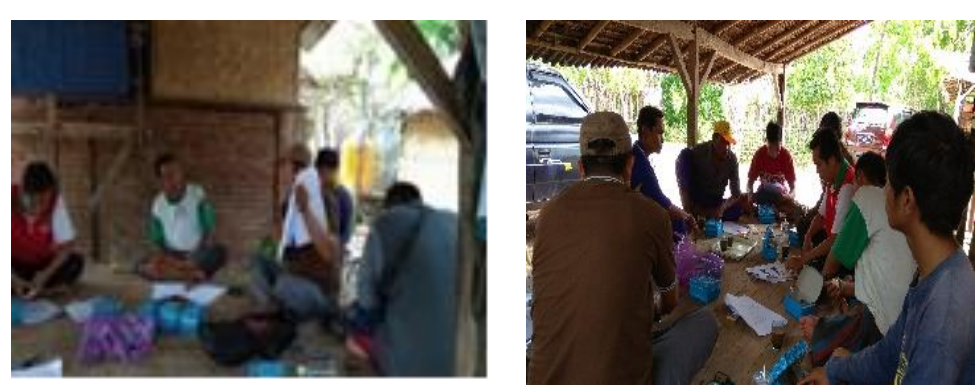

Gambar 2. Penyuluhan tentang irigasi leb pipa 
Pentingnya irigasi yang hemat dilahan kering tujuannya untuk mengungatkan agar masyarakat dapat menggunakan air tanah sebagai air irigasi dengan hemat, karena Sistem irigasi leb pipa menggunakan bahan pipa pvc yang ada dipasaran sekitar.

Pola pembagian irigasi leb pipa lebih proporsional terhadap luas areal, sehingga memungkinkan terjadinya aliran air irigasi yang merata dalam waktu yang pendek. Pada tahap ini Peserta penyuluhan sekaligus mendiskusikan skema sistem jaringan dan bahan-bahan yang diperlukan untuk jaringan irigasi leb pipa.

Tabel 1. Kebutuhan bahan Pipa pvc Lahan 0,5 Are

\begin{tabular}{cllc}
\hline No & Uraian Bahan & Satuan & Jumlah \\
\hline 1 & Pipa 2,5” & lonjor & 4,5 \\
2 & T 2,5” & biji & 3 \\
3 & L2,5” & biji & 6 \\
4 & Dop 2,5 “ & & 6 \\
5 & Sok 2,5” & biji & 3 \\
\hline
\end{tabular}

Sumber: data lapangan

Tabel 2. Kebutuhan bahan Pipa pvc Lahan 1 Are

\begin{tabular}{cllc}
\hline No & Uraian Bahan & Satuan & Jumlah \\
\hline 1 & Pipa 2,5” & lonjor & 4,5 \\
2 & T 2,5” & biji & 4 \\
3 & L2,5” & biji & 8 \\
4 & Dop 2,5” & biji & 8 \\
5 & Sok 2,5” & biji & 3 \\
\hline
\end{tabular}

Sumber: data lapangan

\section{Tahapan Pelaksanaan}

Pada tahapan ini masyarakat yang telah ditentukan warga melakukan pembuatan jaringan irigasi leb pipa di lahan, sesuai dengan skema jaringannya dan bentuk petakan lahan. Kegiatan dilakukan dengan pengukuran jarak tepi (pematang) lahan ke jaringan pipa, setelah itu dipasang tali rapia sebagai skema jalur pipa di lahan yang akan digali oleh warga. Setelah siap, selanjutnya dilakukan pengalian jalur pipa sedalam $60 \mathrm{~cm}$. Setelah jalur pipa selesai digali kemudian dilakukan pemasangan pipa pvc 2,5“ dan pemasangan sambungan $T$ untuk keluarnya aliran irigasi ke permukaan lahan. Pelaksanaan pembuatan jaringan irigasi leb pipa ditunjukkan pada Gambar 3. seperti pada Gambar 4, berikut
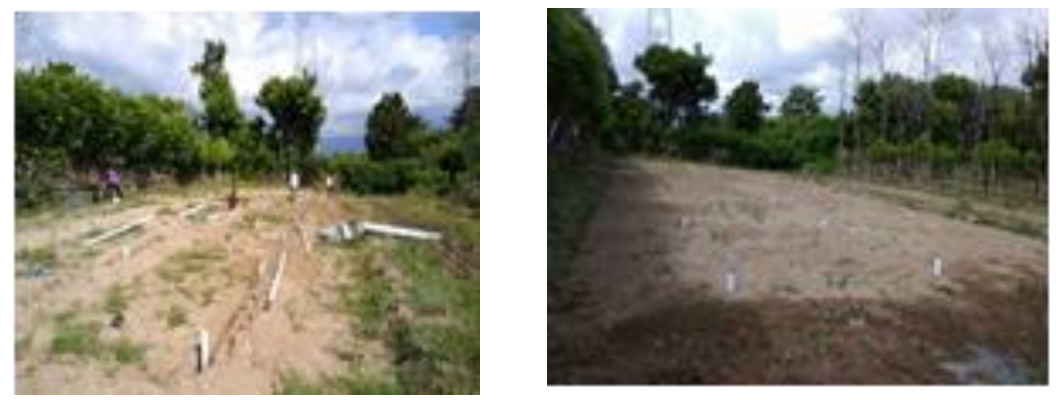

Gambar 3. Pembuatan Jaringan Irigasi leb pipa 
Setelah dipasang jaringan irigasi leb terlihat posisi pipa leb yang muncul ke permukaan lahan sebagai tempat keluarnya air irigasi tampak lebih merata. Pipa tersebut kemudian dipotong agar rata dengan tanah sehingga memungkinan air terdistribusi dilahan dengan cepat dan merata.

\section{Tahapan Evaluasi}

Tinjauan lapangan kembali dilakukan tim setelah penyuluhan dan pelatihan dilakukan beberapa minggu yang lalu, untuk melihat penggunaan sistem irigasi leb pipa pada usaha pertanian warga. Aplikasi irigasi telah diterapkan pada usahatai tanaman sorgum dan tanaman cabe, sedangakn kegiatan tinjauan lapangan pada pertanian sorgum ditunjukkan pada gambar berikut.

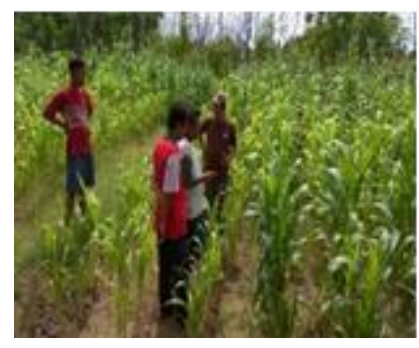

Gambar 4. Aplikasi Irigasi leb pia pada Sorgum
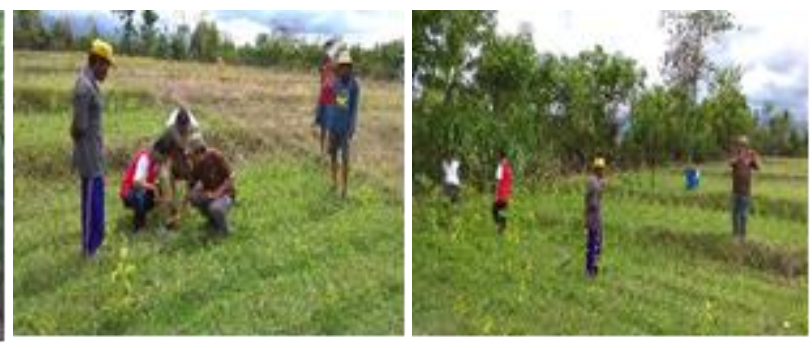

Gambar 6. Aplikasi Irigasi lep pipa pada cabe

Aplikasi irigasi pada lahan sorgum sudah menunjukkan fakta bahwa irigasi dilakukan lebih cepat dan hasil pembasahannya lebih merata. Untuk aplikasi irigasi pada tanaman cabe pada tanahnya pasiran dimana petakan lahannya masih minim unsur haranya, pemberian irigasi dapat dilakukan lebih merata. Akan tetapi karena tanahnya tidak kuat menahan air maka irigasi dilakukan lebih sering dalam durasi yang pendek.

Untuk irigasi pada tanaman sorgum, irigasi hanya diperlukan selama 30 menit saja. Tahapan ini beberapa waktu kemudian dilakukan pengecekan lapangan untuk melihat aplikasi irigasi ini pada tanaman. Aplikasi jaringan irigasi yang diuji coba pada tanaman sorgum, diketahui lama irigasi sistem leb lebih cepat dari pada menggunaan bok JIAT karena diberikan satu bok saja pada luas lahan sekitar 1 ha. Berdasarkan hasil pengujian irigasi ditingkat lapangan menunjukkan bahwa dalam penggunaan irigasi sistem JIAT diperlukan waktu selama 3 jam kedalaman irigasi lebih tidak merata, sedangkan irigasi lahan menggunakan sistem leb pipa diperlukan waktu kurang dari 2 jam dengan kedalaman irigasi relatif merata.

\section{KESIMPULAN DAN SARAN}

\section{Kesimpulan}

Hasil pengabdian ini menunjukkan bahwa, masyarakat tani Arungan Bali telah mendapatkan pengetahuan pentingnya irigasi dan dapat membuat jaringan irigasi leb pipa di petak lahan. Masyarakat dapat membuat jaringan irigasi leb pipa secara swadaya karena contohnya sudah ada di lahan warga. Sistem irigasi leb pipa dapat menghemat biaya irigasi sekitar 30\% dari cara yang sudah ada. 


\section{Saran}

Saran yang dapat diberikan bahwa untuk aplikasi irigasi lep pipa pada lahan yang poros air irigasi perlu dilakukan berkali-kali dalam waktu yang pendek guna meningkatkan efisiensi air, dan pemberian irigasi dapat disesuaikan dengan pertumbuhan tanaman terutama panjang akarnya.

\section{Ucapan Terima Kasih}

Kami mengucapkan terimakasih atas terselenggaranya kegiatan ini di dusun Arungan bali Desa AkarAkar, kepada LPPM Unram yang telah mambantu dana kegiatan ini dan masyarakat Arungan Bali dengan pemilik lahan telah ikut mensukseskan pelaksanaan penyuluhan ini di lapangan.

\section{DAFTAR PUSTAKA}

Anonim, 2008, "Seri Modul No:PPA 1/22, 2008 ” Pengenalan Sistem Irigasi,"Edisi November, DPU.JICA

Anonim, 2008,"Seri Modul No:PPA 5/22, 2008 "Rencana Tata Tanam,"Edisi November, DPU.JICA.

Jaya Negara, Anid Supriyadi,2016,"Analsis rancang bangun sistem irigasi hemat air terpadu berbasis jaringan Irigasi air Tanah (JIAT) pada Lahan Kering Tanah Bergradasi Halus, di Pringgabaya Kabupaten Lombok Timur, Laporan Penelitian Hibah Bersaing, Unram, Mataram. 